\title{
Effects of Graphite Content and Temperature on Microstructure and Mechanical Properties of Iron-Based Powder Metallurgy Parts
}

\author{
Xiaoxun Zhang ${ }^{1}$, Fang $\mathrm{Ma}^{2}$, Kai $\mathrm{Ma}^{1} \&{\mathrm{Xia} \mathrm{Li}^{1}}^{1}$ \\ ${ }^{1}$ School of Materials Engineering, Shanghai University of Engineering Science, Shanghai, China \\ ${ }^{2}$ College of Automotive Engineering, Shanghai University of Engineering Science, Shanghai, China \\ Correspondence: Xiaoxun Zhang, School of Materials Engineering, Shanghai University of Engineering Science, \\ 333 Longteng Road, Songjiang District, Shanghai 201620, China. Tel: 86-139-1779-2182. E-mail: \\ xx.zhang.cn@gmail.com
}

Received: July 23, 2012 Accepted: August 10, 2012 Online Published: August 23, 2012

doi:10.5539/jmsr.v1n4p48 URL: http://dx.doi.org/10.5539/jmsr.v1n4p48

\begin{abstract}
An experimental investigation was conducted to study the effects of graphite content and temperature on the microstructure and mechanical properties of iron-based powder metallurgy parts. The specimens were produced at two sintering temperatures, $600^{\circ} \mathrm{C}$ and $1100^{\circ} \mathrm{C}$, respectively, and the graphite contents were $0.5 \%, 1 \%, 1.5 \%$ and $2 \%$, respectively. The polished and etched specimens were examined by optical metallography (OM) and scanning electron microscopy (SEM). Brinell hardness of the sintered specimen was measured to evaluate the mechanical behavior, and the density and the porosity of the specimens were calculated to evaluate the compaction and sintering. The results show that: (1) as the graphite content increasing from $0.5 \%$ to $2 \%$, the microstructure of the iron-based powder sintered specimen changes gradually from ferrite and a small amount of pearlite to pearlite and a small amount of ferrite, (2) with the sintering temperature increasing, the microstructure of the sintered interface becomes uniform, (3) with the graphite content increasing, the hardness of the iron-based powder sintered part grows obviously and (4) the densities of the specimens with different graphite contents at $1100^{\circ} \mathrm{C}$ are higher than those at $600^{\circ} \mathrm{C}$, and with graphite content increasing, the porosity of the sintered specimen decreases.
\end{abstract}

Keywords: graphite content, temperature, microstructure, mechanical property, powder metallurgy

\section{Introduction}

Powder metallurgy (PM) processing consists of an initial compression of the metal powder followed by the heat treatment process of sintering. In the last few decades, a number of investigations on powder metallurgy of porous metals and alloys having a controlled porosity have been conducted (Abyaneh et al., 2007, 2008; Tognana et al., 2009; Canavese et al., 2012). The density, hardness and strength of the sintered compacts were determined by Guo et al. (1997) as a function of weight percent of aluminium-fly ash particles. Sintering of iron powder with graphite, iron powder with copper and graphite, iron powder with nickel and graphite, iron powder with phosphorus, and iron powder with boron was studied by Narasimhan (2001). Mechanical properties of the sintered parts were presented along with application of these parts. Akhlaghi and Pelaseyyed (2004) developed an "in-situ powder metallurgy" technique to produce aluminum alloy-graphite (Al/Gr) composites. A method of making iron-carbon materials in order to obtain materials with a low content of impurities (especially oxygen) and sufficiently high density was developed by Kostikov et al. (2008). The influence of graphite content on the dry sliding and oil impregnated sliding wear characteristics of sintered aluminum 2024 alloy-graphite (Al/Gr) composite materials had been assessed using a pin-on-disc wear test by Akhlaghi and Zare-Bidaki (2009).

Using a sintering process, the physical and mechanical properties of pressed and sintered iron-based materials can be improved. Particle bonding and alloying by diffusion occur during sintering with property enhancements. The effects of sintering are visible as changes in microstructural features, such as particle boundaries and pore edges. Some of the improvements in sintering appear as a loss in particle boundaries, smoother pore edges, and a lessening in the number of angular features between particles. The appearance of these features and characteristics, in conjunction with their frequency of occurrence, is often referred to as degree-of-sinter. Quantification of the degree-of-sinter can be performed on properly prepared metallographic specimens using well-understood stereological practices. 
In this paper, the experimental study was conducted for the effects of graphite content and temperature on the microstructure and mechanical properties of iron-based powder metallurgy parts. The polished and etched specimens were examined by optical metallography (OM) and scanning electron microscopy (SEM). Brinell hardness of the sintered specimen was measured to evaluate the mechanical behavior, and the density and the porosity of the specimens were calculated to evaluate the compaction and sintering.

\section{Experimental Procedures}

\subsection{Materials Preparation}

In order to obtain iron-based powder metallurgy specimens and study the effects of graphite content and temperature on its microstructure and mechanical properties, the iron powder and the graphite powder were prepared. The chemical composition (wt.\%) of the iron powder and the graphite powder were given in Table 1 and Table 2, respectively. These powders were mixed as four groups according to the following steps: (1) 19.9g, $19.8 \mathrm{~g}, 19.7 \mathrm{~g}$ and $19.6 \mathrm{~g}$ of iron powder were weighed respectively and tiled in the container, (2) $0.1 \mathrm{~g}, 0.2 \mathrm{~g}, 0.3 \mathrm{~g}$ and $0.4 \mathrm{~g}$ of graphite powder were weighed respectively and evenly spread over the corresponding groups of iron powder and (3) the four groups of $20 \mathrm{~g}$ of iron and graphite powder were stired well and mixed uniformly. Then, four groups of powder mixtrure were produced and their graphite contents were $0.5 \%, 1 \%, 1.5 \%$ and $2 \%$, respectively. These powder mixtrures were used to make compact specimen in the experiments.

Table 1. The main chemical composition of the iron powder (mass fraction, \%)

\begin{tabular}{cccccccc}
\hline Element & $\mathrm{Fe}$ & $\mathrm{Cu}$ & $\mathrm{SO}$ & $\mathrm{NO}$ & Sulfuric acid insolubles & Water insolubles & Other \\
\hline wt. $\%$ & 98.0 & 0.005 & 0.05 & 0.005 & 0.1 & 0.1 & 1.74 \\
\hline
\end{tabular}

Table 2. The main chemical composition of the graphite powder (mass fraction, \%)

\begin{tabular}{ccccc}
\hline Element & $\mathrm{C}$ & $\mathrm{Fe}$ & $\mathrm{H}_{2} \mathrm{O}$ & Other \\
\hline wt. $\%$ & 98.0 & 0.045 & 0.5 & 1.455 \\
\hline
\end{tabular}

\subsection{Sample Production}

\subsubsection{Powder Compaction}

A cylindrical mold with a diameter of $16 \mathrm{~mm}$ was adopted to compact the powder. The cotton with alcohol was used to wipe and clean the mold wall. Powder mixtrure of $5.0 \mathrm{~g}$ was weighed and put into the mold. A hydraulic press was used to compact the powder and the load on the die was 5 ton and the holding time was 2 minutes. Then, the compacted specimen was ejected from the mold.

\subsubsection{Powder Sintering}

The specimens were sintered in a vacuum sintering furnace at the experimental center of material engineering of shanghai university of engineering science. Two different sintering conditions were adopted: (1) heating time was one hour and heating the specimens to $600^{\circ} \mathrm{C}$, the holding time was two hours and then cooling with the furnace and (2) heating time was two hours and 20 minutes and heating the specimens to $1100^{\circ} \mathrm{C}$, the holding time was two hours and then cooling with the furnace.

\subsubsection{Metallographic Specimen Preparation}

The sintered specimens were cutted longitudinally into two parts on the metallographic cutter. The cut specimens were used to produce metallographic specimen and the operating time for a metallographic specimen was 10 to 15 minutes. The metallographic specimens were polished and then etched by $4 \%$ nitric acid alcohol solution.

\subsection{Microstructure Observation}

In this study, both temperature and graphite content were considered as the effective factors on the microstructure and mechanical properties of the sintered specimen. The specimens were produced at two sintering temperatures, $600^{\circ} \mathrm{C}$ and $1100^{\circ} \mathrm{C}$, respectively, and with four graphite contents, $0.5 \%, 1 \%, 1.5 \%$ and $2 \%$, respectively. The polished and etched specimens were examined by optical metallography (OM) and scanning electron microscopy (SEM) and the magnification was 400 . The effects of temperature and graphite content on the microstructure of the iron-based powder sintered products by metallographic analysis were shown 
in Figure 1 and Figure 2, respectively.

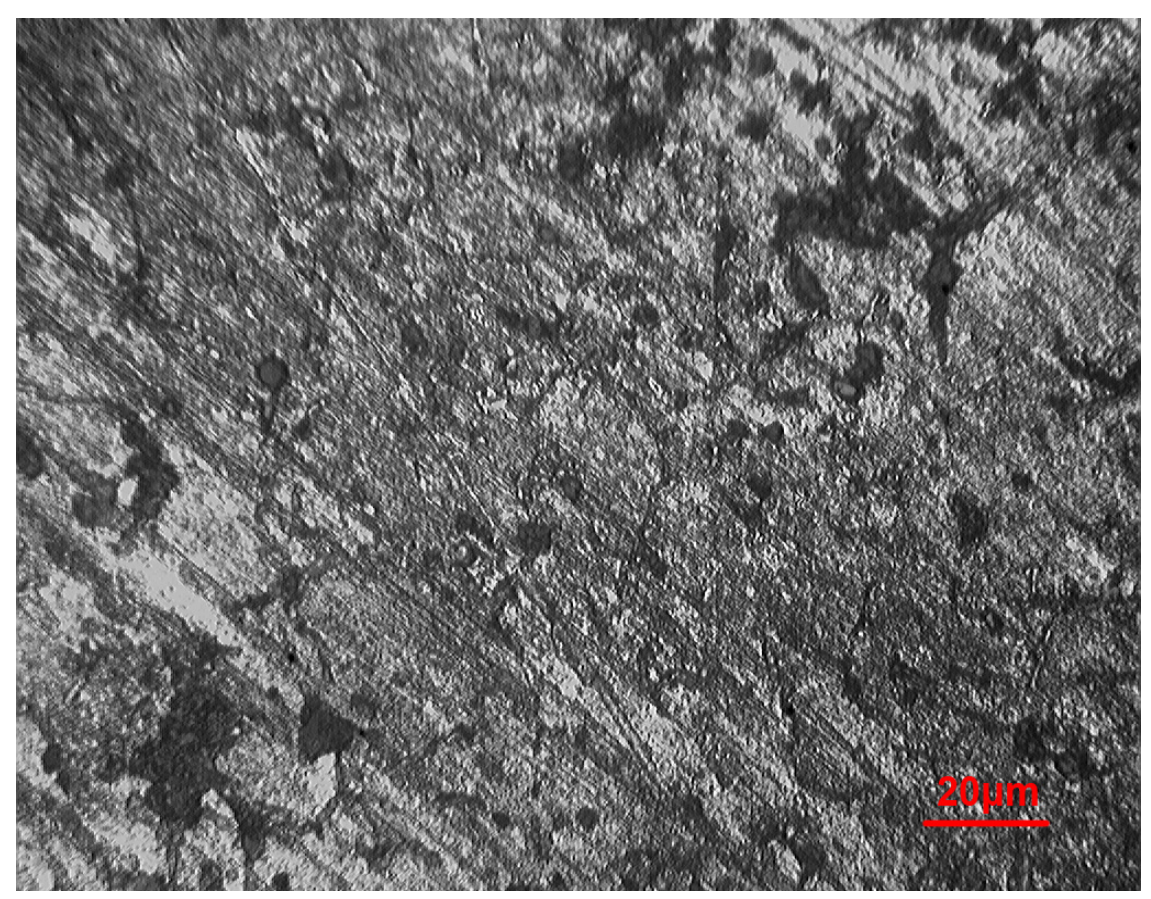

(a)



(b) 




(c)

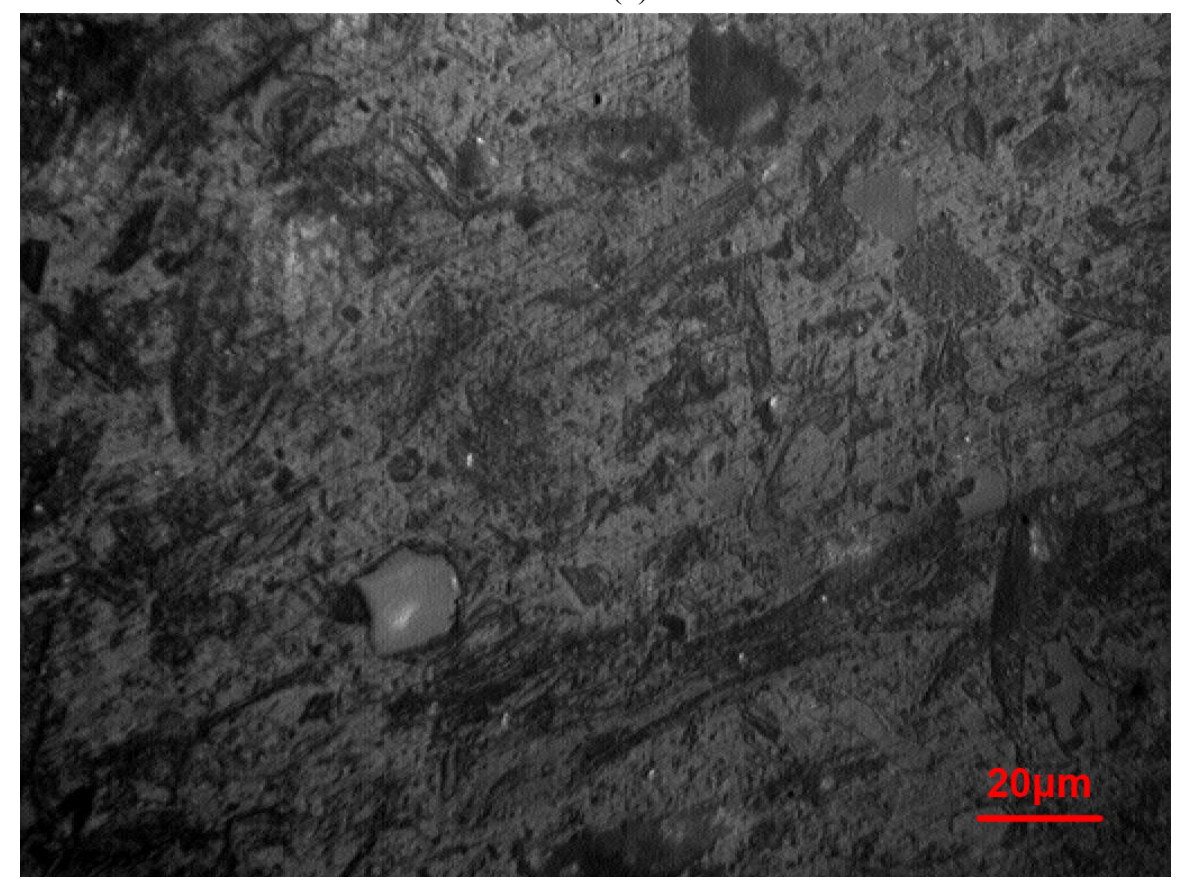

(d)

Figure 1. Microstructure of the iron-based PM parts sintered at $600{ }^{\circ} \mathrm{C}$ with different graphite content: (a) $0.5 \%$, (b) $1.0 \%$, (c) $1.5 \%$ and (d) $2.0 \%$ 


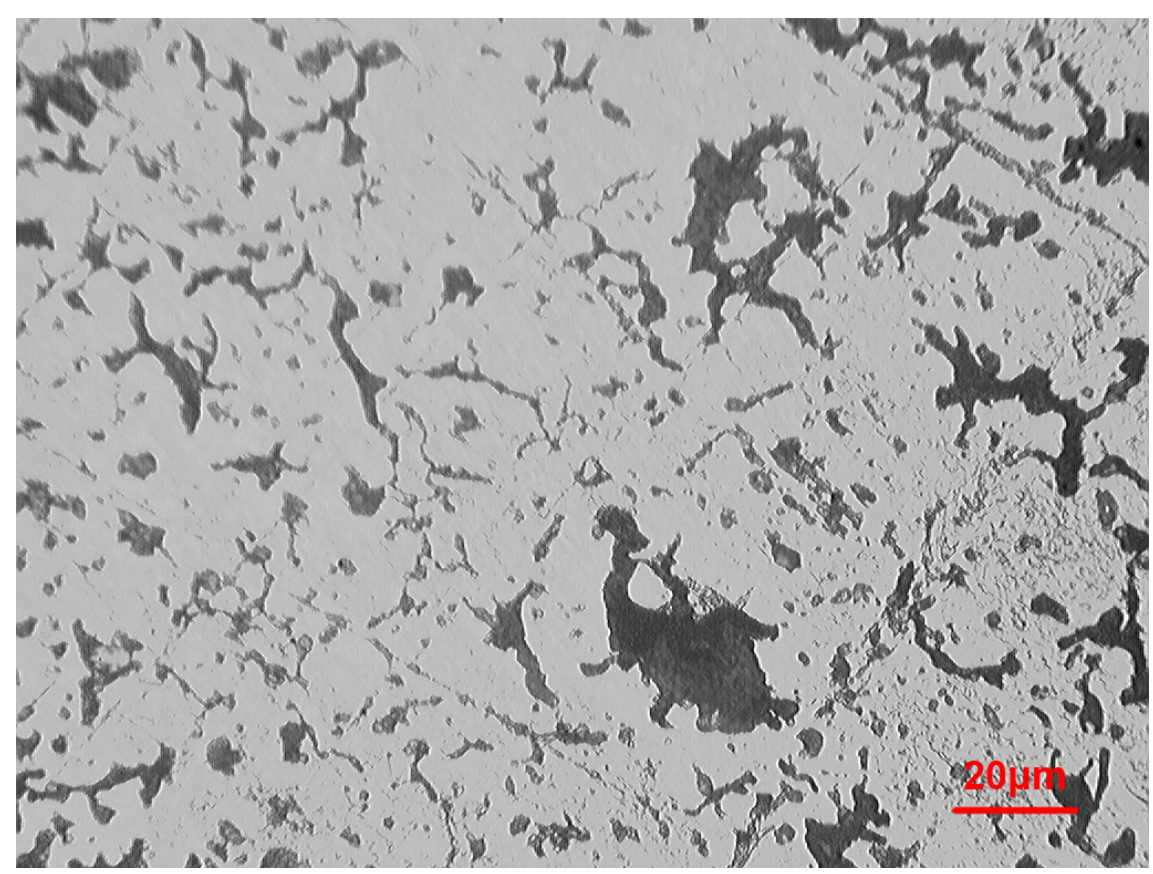

(a)

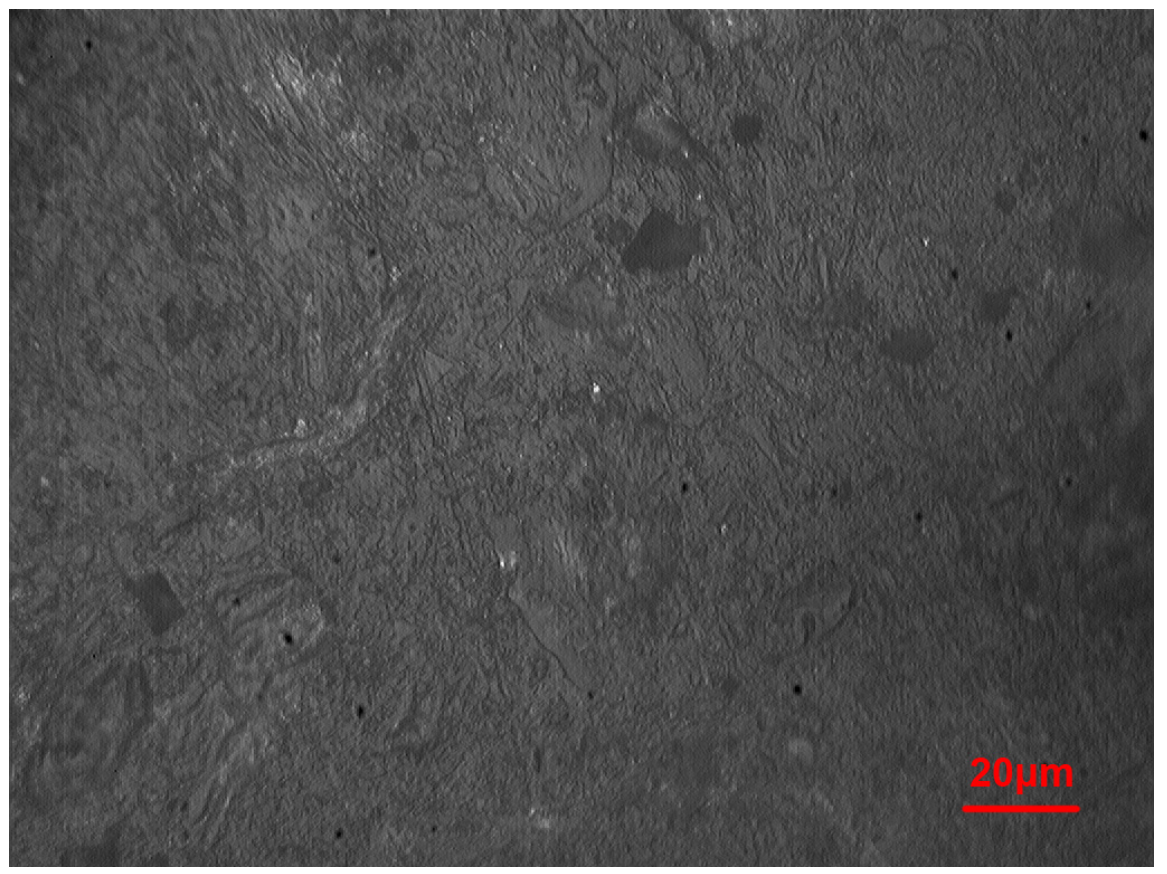

(b) 


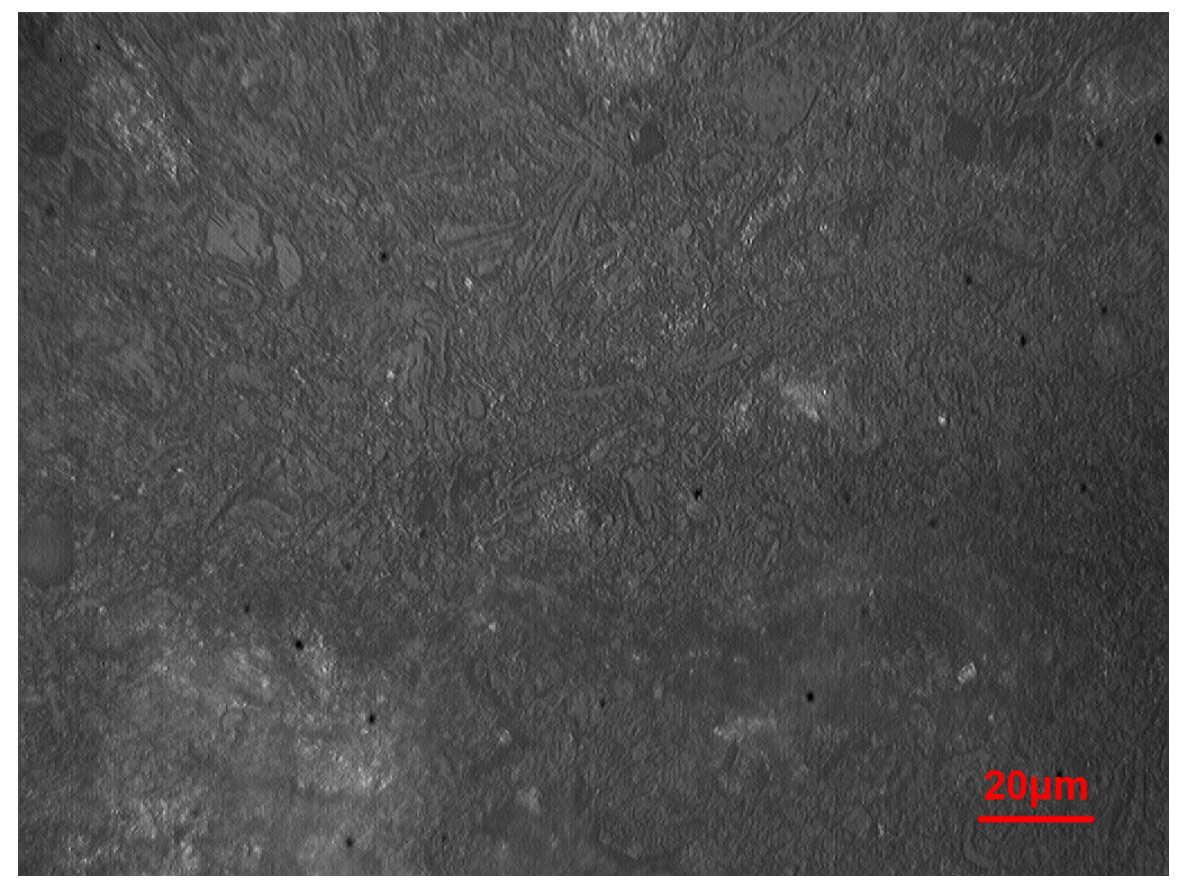

(c)

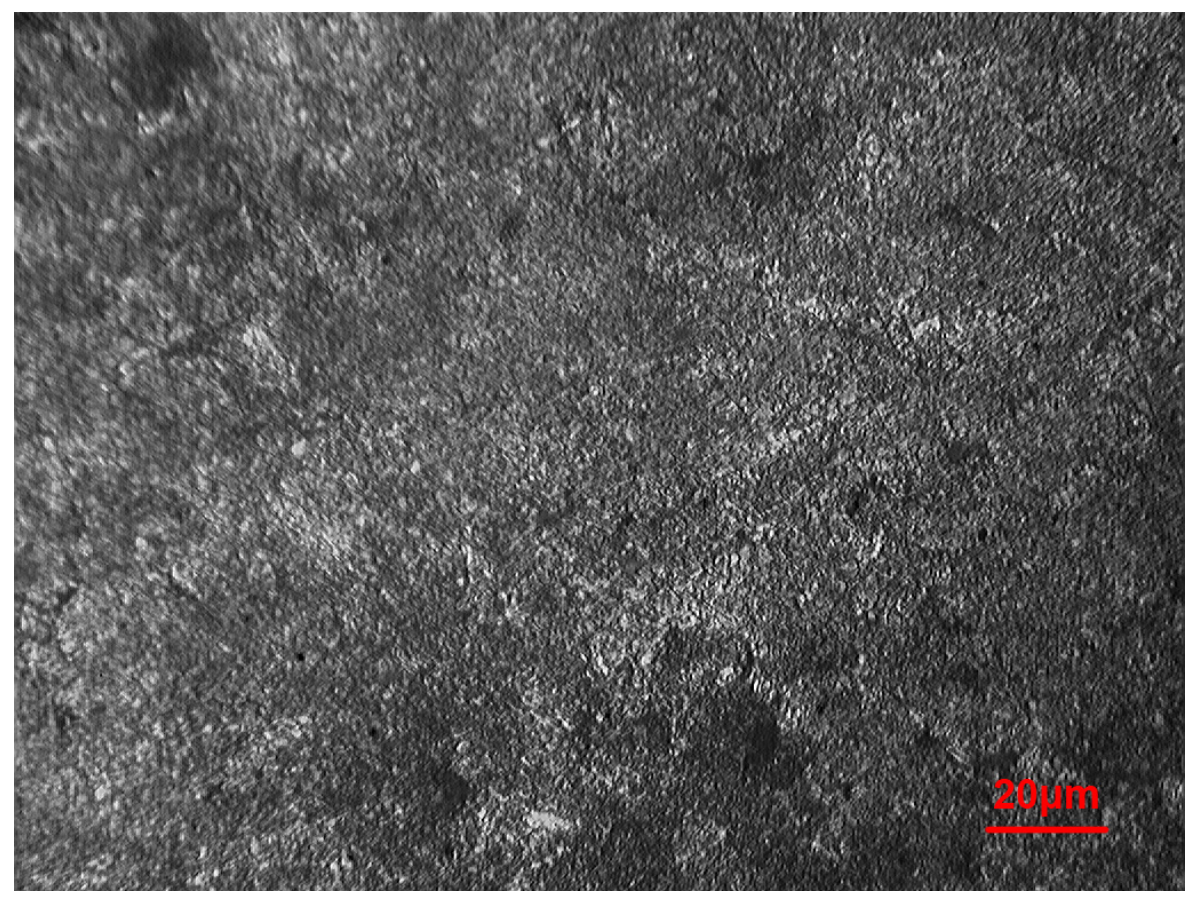

(d)

Figure 2. Microstructure of the iron-based PM parts sintered at $1100^{\circ} \mathrm{C}$ with different graphite content (a) $0.5 \%$, (b) $1.0 \%$, (c) $1.5 \%$ and (d) $2.0 \%$

\subsection{Mechanical Property Characterization}

Brinell hardnesses of the sintered specimens were measured to evaluate the mechanical behavior of the sintered material under different sintering conditions. A spherical indenter with the diameter of $5 \mathrm{~mm}$ was adopted and the load was 3 ton. After the load had been holding for 10 seconds, the indenter was removed and the indentation was measured to obtain the data for HBW ( $\mathrm{H}$ from hardness, B from brinell and $\mathrm{W}$ from the material of the indenter, tungsten (wolfram) carbide) calculation. The HBWs of the sintered specimens under different conditions were calculated and the effects of temperature and graphite content on the HBW of the sintered 
specimens were shown in Figure 3.

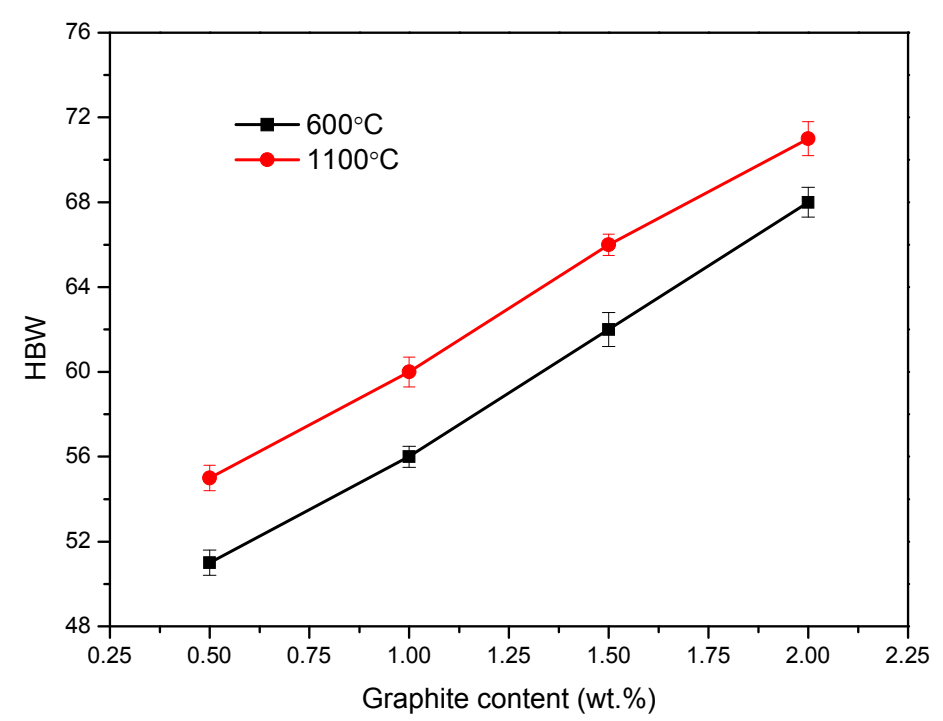

Figure 3. The effects of temperature and graphite content on the HBW of the sintered specimens

\section{Results and Discussion}

\subsection{Microstructures}

The microstructures of the sintered specimens with the graphite content from $0.5 \%$ to $2 \%$ were shown in Figure 1 and Figure 2. It can be seen that as the graphite content increases from $0.5 \%$ to $2 \%$, the microstructure of the iron-based powder sintered specimen changes gradually from ferrite (white microstructure) and a small amount of pearlite (black and white lamellar microstructure) to pearlite and a small amount of ferrite. A small amount of cementite $\left(\mathrm{Fe}_{3} \mathrm{C}\right)$ also appeared in the microstructure when the graphite content increased to $2 \%$. It also can be seen that the austenite grain size increases gradually when the graphite content increases. This is mainly because that the degree of superheat increases as the graphite content increases when the sintering temperature is constant, thus contributing to the growth of austenite grain.

Comparing the microstructures of the sintered specimens at $600^{\circ} \mathrm{C}$ with those at $1100^{\circ} \mathrm{C}$ from Figure 1 and Figure 2, it can be concluded that with the sintering temperature increasing, the microstructures of the sintered interface become uniform. This is mainly because of the formation of many meshes of grain boundary and their interactions with the interwoven pores. The excess vacancies at the edge of the sintering neck and on the surface of micro-pores are easy to pass the adjacent grain boundary and diffuse or absorb. The higher the sintering temperature, the greater the coefficient of the atomic diffusion within the particle, and the faster the sintering carried out.

\subsection{Mechanical Behavior}

When the graphite was added to the iron-based powder, $\mathrm{Fe}_{3} \mathrm{C}$ appeared in the sintered parts and it formed a very hard and brittle surface layer, so that the existence of $\mathrm{Fe}_{3} \mathrm{C}$ had a hardening effect. It is shown in Figure 3 that with the increase of graphite content, the hardness of the iron-based powder sintered parts shows obvious growth both at $600^{\circ} \mathrm{C}$ and $1100^{\circ} \mathrm{C}$. At the temperature of $600^{\circ} \mathrm{C}$ and the graphite content from $0.5 \%$ to $2.0 \%$, the hardness of the iron-based powder sintered parts increases from $51 \mathrm{HBW}$ to $68 \mathrm{HBW}$, and at temperature of $1100^{\circ} \mathrm{C}$ the hardness increases from $55 \mathrm{HBW}$ to $71 \mathrm{HBW}$. The hardness gradually increases because the lattice distortion of the ferrite and the formation of the $\mathrm{Fe}_{3} \mathrm{C}$ which caused by graphite in the iron-based powder sintered parts. However, the hardnesses of the specimens at $600^{\circ} \mathrm{C}$ are smaller than those at $1100^{\circ} \mathrm{C}$, because the strengthening effect of $\mathrm{Fe}_{3} \mathrm{C}$ seems to be weaker than the role of lattice distortion.

\subsection{Density and Porosity}

The dimensions and the weight of the sintered specimens were measured and then their density and porosity were calculated. The corresponding dimensions and weight of the specimens were displayed in Table 3 . The 
density of the specimen can be calculated by

$$
\rho=\frac{M}{V}=\frac{4 M}{\pi D^{2} H}
$$

where $M, V$ and $\rho$ are the mass, the volume and the density of the sintered specimen, respectively, and $D, H$ are the diameter and height of the sintered specimen, respectively.

The porosity of the specimen can be calculated by

$$
J=\frac{V_{P}}{V}=\frac{V-V_{T}}{V}
$$

where $V_{P}, V$ and $J$ are the volume of the pores in the specimen, the volume and the porosity of the sintered specimen, respectively, and $V_{T}$ is the theoretical volume of the sintered specimen which can be obtained by

$$
V_{T}=\frac{M_{\mathrm{Fe}}}{\rho_{\mathrm{Fe}}}+\frac{M_{C}}{\rho_{C}}
$$

where $M_{\mathrm{Fe}}$ and $M_{C}$ are the mass of the iron and graphite, respectively, and $\rho_{\mathrm{Fe}}$ and $\rho_{C}$ are the density of the iron and the graphite, respectively.

The density and the porosity of the specimen were calculated and displayed in Table 3. It can be seen from Table 3 that: (1) the densities of the specimens with different graphite contents at $1100^{\circ} \mathrm{C}$ are higher than those at $600^{\circ} \mathrm{C}$, (2) with graphite content increasing, the porosity of the sintered specimen decreasing both at $600^{\circ} \mathrm{C}$ and at $1100^{\circ} \mathrm{C}$. It indicates that the higher the temperature, the higher the density, and the higher the graphite content, the lower the porosity of the iron-based powder metallurgy parts.

Table 3. The density and porosity of the sintered specimen

\begin{tabular}{cccccccc}
\hline $\begin{array}{c}\text { Specimen } \\
\text { No. }\end{array}$ & $\begin{array}{c}\text { Temperature } \\
\left({ }^{\circ} \mathrm{C}\right)\end{array}$ & $\begin{array}{c}\text { Graphite content } \\
(\mathrm{wt} . \%)\end{array}$ & $\begin{array}{c}\text { Diameter } \\
(\mathrm{mm})\end{array}$ & $\begin{array}{c}\text { Height } \\
(\mathrm{mm})\end{array}$ & $\begin{array}{c}\text { Mass } \\
(\mathrm{g})\end{array}$ & $\begin{array}{c}\text { Density } \\
\left(\mathrm{g} / \mathrm{cm}^{3}\right)\end{array}$ & $\begin{array}{c}\text { Porosity } \\
(\%)\end{array}$ \\
\hline 1 & 600 & 0.5 & 16.0 & 4.1 & 5.0 & 6.07 & 21.88 \\
2 & 600 & 1.0 & 16.0 & 4.0 & 5.0 & 6.22 & 18.94 \\
3 & 600 & 1.5 & 16.0 & 4.0 & 5.0 & 6.22 & 17.96 \\
4 & 600 & 2.0 & 16.0 & 4.0 & 5.0 & 6.22 & 16.98 \\
5 & 1100 & 0.5 & 16.0 & 3.9 & 5.0 & 6.38 & 17.87 \\
6 & 1100 & 1.0 & 16.0 & 3.8 & 5.0 & 6.54 & 14.68 \\
7 & 1100 & 1.5 & 16.0 & 3.8 & 5.0 & 6.54 & 13.65 \\
8 & 1100 & 2.0 & 16.0 & 3.8 & 5.0 & 6.54 & 12.61 \\
\hline
\end{tabular}

\section{Conclusions}

(1) As the graphite content increases from $0.5 \%$ to $2 \%$, the microstructure of the iron-based powder sintered specimen changes gradually from ferrite and a small amount of pearlite to pearlite and a small amount of ferrite. The austenite grain size increases gradually when the graphite content increases.

(2) With the sintering temperature increasing, the microstructures of the sintered interface become uniform. The higher the sintering temperature, the greater the coefficient of the atomic diffusion within the particles, and the faster the sintering carried out.

(3) With the graphite content increasing, the hardness of the iron-based powder sintered parts grows obviously both at $600^{\circ} \mathrm{C}$ and $1100^{\circ} \mathrm{C}$. The hardness gradually increases because the lattice distortion of the ferrite and the formation of the $\mathrm{Fe}_{3} \mathrm{C}$ which caused by graphite in the iron-based powder sintered parts. However, the strengthening effect of $\mathrm{Fe}_{3} \mathrm{C}$ seems to be weaker than the role of lattice distortion.

(4) The densities of the specimens with different graphite contents at $1100^{\circ} \mathrm{C}$ are higher than those at $600^{\circ} \mathrm{C}$, and with graphite content increasing, the porosity of the sintered specimen decreases both at $600^{\circ} \mathrm{C}$ and at $1100^{\circ} \mathrm{C}$. 


\section{Acknowledgements}

This work is supported by Shanghai Leading Academic Discipline Project under grant J51402 and supported by Innovation Program of Shanghai Municipal Education Commission under grant 12ZZ183 and supported by Science Foundation for the Excellent Youth Scholars of Shanghai Municipal Education Commission under grant gjd10008.

\section{References}

Abyaneh, M. K., \& Kulkarni, S. K. (2008). Giant piezoresistive response in zinc-polydimethylsiloxane composites under uniaxial pressure. Journal of Physics D: Applied Physics, 41(13), 135405-135412. http://dx.doi.org/10.1088/0022-3727/41/13/135405

Abyaneh, M. K., Paramanik, D., Varma, S., Gosavi, S. W., \& Kulkarni, S. K. (2007). Formation of gold nanoparticles in polymethylmethacrylate by UV irradiation. Journal of Physics D: Applied Physics, 40(12), 3771-3779. http://dx.doi.org/10.1088/0022-3727/40/12/032

Akhlaghi, F., \& Pelaseyyed S. A. (2004). Characterization of aluminum/graphite particulate composites synthesized using a novel method termed "in-situ powder metallurgy". Materials Science and Engineering: A, 385(1-2), 258-266. http://dx.doi.org/10.1016/j.msea.2004.06.050

Akhlaghi, F., \& Zare-Bidaki, A. (2009). Influence of graphite content on the dry sliding and oil impregnated sliding wear behavior of Al 2024-graphite composites produced by in situ powder metallurgy method. Wear, 266(1-2), 37-45. http://dx.doi.org/10.1016/j.wear.2008.05.013

Canavese, G., Stassi, S., Stralla, M., Bignardi, C., \& Pirri, C. F. (2012). Stretchable and conformable metalpolymer piezoresistive hybrid system. Sensors and Actuators A: Physical. http://dx.doi.org/10.1016/j.sna.2012.01.037

Guo, R. Q., Rohatgi, P. K., \& Nath, D. (1997). Preparation of aluminium-fly ash particulate composite by powder metallurgy technique. Journal of Materials Science, 32(15), 3971-3974. http://dx.doi.org/10.1023/A:1018625118090

Kostikov, V. I., Dorofeev, V. Yu., Chumak-Zhun', D. A., Ul’yanovskii, A. P., Eremeeva, Zh. V., \& Yaitskii, D. L. (2008). Reduction of oxide films during consolidation of the charge used to make powder semifinished products. Metallurgist, 52(7-8), 415-419. http://dx.doi.org/10.1007/s11015-008-9079-y

Narasimhan, K. S. (2001). Sintering of powder mixtures and the growth of ferrous powdermetallurgy. Materials Chemistry and Physics, 67(1-3), 56-65. http://dx.doi.org/10.1016/S0254-0584(00)00420-X

Tognana, S., Salgueiro, W., Somoza, A., Pomarico, J. A., \& Ranea-Sandoval, H. F. (2009). Influence of the filler content on the thermal expansion behavior of an epoxy matrix particulate composite. Materials Science and Engineering B, 157, 26-31. http://dx.doi.org/10.1016/j.mseb.2008.12.003 